\title{
MODIFIED STEINER-WEBER PROBLEM WITH ADDITIONAL RESTRICTIVE CONDITIONS
}

\author{
[Modifikovaný Steiner-Weberův problém s přidanými omezujícími \\ podmínkami] \\ Josef Košt’álek ${ }^{1}$, Pavla Kot’átková Stránská \\ ${ }^{I}$ CTU in Prague, Faculty of Mechanical Engineering, Karlovo náměstí 13, 12135 Prague 2 \\ Email: josef.kostalek@fs.cvut.cz \\ ${ }^{2}$ CTU in Prague, The Masaryk Institute of Advanced Studies, Kolejni 2637/2a, 16000 Prague 6 \\ Email: pavla.kotatkova.stranska@cvut.cz.
}

\begin{abstract}
Smartcities are, among other things, well-known for solving optimization problems. One of the problems could be an optimal location of a central warehouse, which supplies branches. The branches are not the same; they naturally have a different location and a volume of traffic. The central warehouse must be situated in the area within the optimal distance that allows for minimal transportation costs. It can happen that the optimal solution to the abovementioned problem lies in a prohibited area such as forests, military areas. This paper deals with the problem of an optimal location of the central warehouse that must not lie in the prohibited area. The aim of the article is to present a mathematical model based on nonlinear principle, which can offer a solution to the mentioned problem. The main principle in modelling is to create a user-friendly and affordable model and to find an optimal solution to a particular situation. Such a model must take into consideration the dynamic development of logistics, construction of distribution warehouses and the chain stores nearby. The model gives results for the first phase of the planning optimal positioning. The mathematical solution must be implemented into a realistic situation. The actual location of the central warehouse must be adapted to, for example the reach of the highway.
\end{abstract}

Keywords: central point, localization, mathematical model, minimization transportation costs, optimal solution, restrictive conditions, warehouse.

JEL classification: O18, R59, C44, C61

Doručeno redakci: 7.6.2018; Recenzováno: 13.6.2018; 30.6.2018; Schváleno k publikování: 19.9.2018

\section{Introduction}

Logistics has recently acquired great significance in the industry due to the rapidly growing interest in Supply Chain Management. One of the important open issues in logistics is the effective integration of logistical components such as transportation cost with facility location models since the two are highly inter-related in practice. In particular, locations, flows, shipment compositions, and shipment cycle times are highly inter-dependent. (Siddhartha 2002).

Research studies are devoted to the development of mathematical models for distribution centre locations. The choice of locations for distribution centres is among the most critical management decisions. Aikens (1985) presented nine basic location models, which included the simple incapacitated facility location model, the capacitated facility location model, the dynamic and stochastic capacitated facility location models etc. All objective functions of these models were created to minimize the transportation costs and were fixed investment costs. Holmberg (1999) studied the exact solution method for the incapacitated facility location problem in which the transportation costs were nonlinear. It considered not only the fixed costs and transportation costs but also the inventory costs, solved by the Dantzig-Wolfe (D-W) decomposition method. Owen and Daskin (1998) considered the dynamic nature of facility 
location problem and the stochastic nature of the customer's demand and developed simple dynamic and stochastic location models. Recently, Klose and Drexl (2005) reviewed some of the contributions to the current state of facility location models for the distribution system. Zhou et al. (2002) investigated the balanced allocation of customers to multiple distribution centres with a genetic algorithm approach. Syam (2002) investigated a model and methodologies for the location problem with logistical components. (Jossef 1985, Siddhartha 2002, Sum 2008).

The article describes possibilities for solving a problem related to the optimal location of the central point (e.g. abovementioned warehouse). This problem can be found in a wide range of industries. It is the location of the central warehouse between stores. The aim is to achieve a minimum total cost. (Gros 1996, Jablonský 2007, Jurová 2016, Kavan 2007).

We solve a mathematical problem where we know the coordinates of the set of points $(1,2$, $3, \ldots, n)$ and the coordinates of the central point are unknown. The problem has only two unknown variables ( $X$ and $Y$ coordinate for the central point). The central point should be placed to minimize the total transportation costs to other points. The problem is complicated by the fact that each fair trade consumes a different amount of goods. If the volume of traffic from a central point into the other points is the same, the central point lays in the geometric centre of gravity in the middle of the set of points. In practice, these situations appear not very often. It is necessary to consider various volumes of transport.

The target location of a central point must comply with the restrictive conditions of defined areas. Concurrently, a solution must fulfil conditions of minimizing overall transport performance (e.g. tonne-kilometre counts). The lower the transport performance (the better the decision), the lower the transportation costs. If the conditions are fulfilled, a higher efficiency of the logistics system can be expected.

\section{The theoretical basis of a mathematical model}

The mathematical model deals with a central point location. It is based on a situation where a central point supply a network of stores and a different quantity of products is transported to each store. The entire mentioned situation is depicted in figure 1.

Figure 1: Location of the central point in a set of point

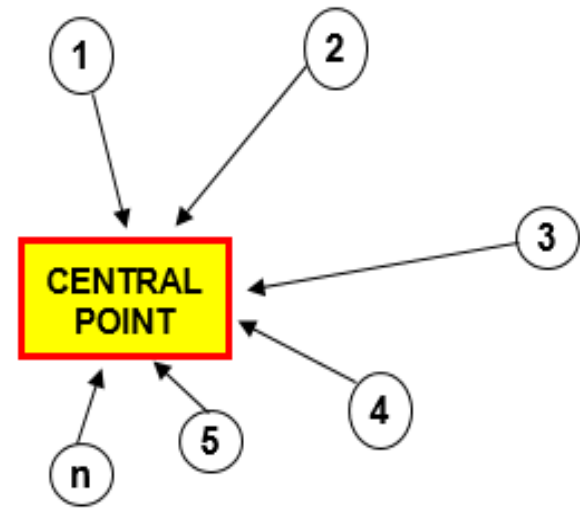

Source: own

The central point is located with respect to the local constraints, respectively the areas with the impossibility of construction. 
The problem is to find a location with minimal costs,

$$
F=\sum_{i=1}^{n} Q_{i} z_{i}=\min
$$

where $i$ is a number of stores, $Q_{i}$ is the volume of traffic from a central point to store $i, z_{i}$ is the distance from a central point to store $i$ and $F$ is an objective function that will minimize transportation costs.

This problem can be seen as linear, but the distance $z_{i}$ is based on Pythagorean Theorem

$$
z_{i}=\sqrt{\left(x-x_{i}\right)^{2}+\left(y-y_{i}\right)^{2}}
$$

where $x$ and $y$ are coordinates of the central point and $x_{i}$ and $y_{i}$ are coordinates of $i$-point (store).

If we combine formula 1 and 2, we obtain

$$
F=\sum_{i=1}^{n} Q_{i} \sqrt{\left(x-x_{i}\right)^{2}+\left(y-y_{i}\right)^{2}}=\min
$$

The described problem is called the Steiner - Weber's problem, see in Rollo (1973). It is not hard to solve it with e.g. MS Excel by employing solver (search for the objective function $F$ ). The article shows the practical application of nonlinear programming using restrictive conditions in the form of implications (if-then).

In figure 2, the shaded area represents the place where the central point cannot be placed. This area can be represented as houses, forests, river, etc. The central point is identified by a square of yellow colour and other sections (e.g. stores) are marked with rings of red colour. Coordinates of the centre point $[x, y]$ are marked with a red colour, where $x$ must not lie within the area $a_{1}$ to $a_{2}$ and $y$ must not lie in area $b_{1}$ to $b_{2}$.

More mathematically,

$$
[x, y] \notin\left(a_{1} ; a_{2}\right) \times\left(b_{1} ; b_{2}\right) .
$$

Unfortunately, this form cannot be written into MS Excel, so these restricted conditions need to be rewritten and transformed. 
Figure 2: Restrictions in the location of the central point

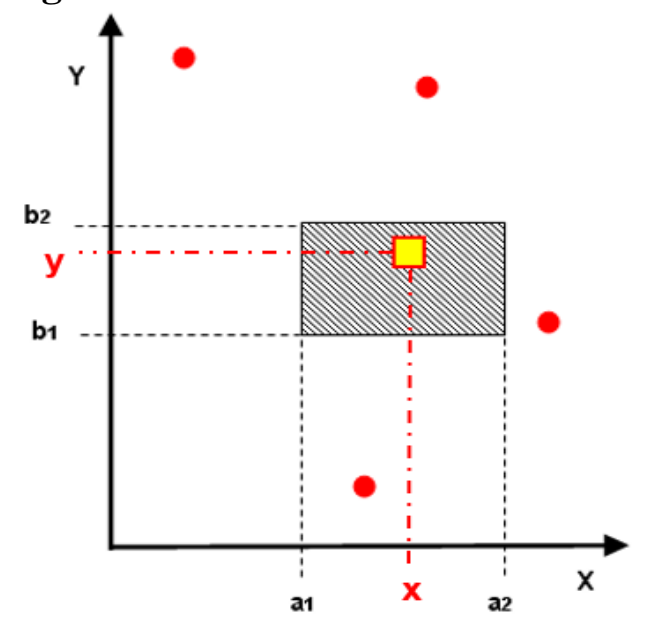

Source: own

The prohibited area is defined as rectangle with coordinates $\left[a_{1}, b_{1}\right],\left[a_{1}, b_{2}\right],\left[a_{2}, b_{1}\right],\left[a_{2}, b_{2}\right]$. Then we calculate the values of $a_{s}$ and $b_{s}$

$$
\begin{aligned}
& a_{s}=\frac{a_{1}+a_{2}}{2}, \\
& b_{s}=\frac{b_{1}+b_{2}}{2} .
\end{aligned}
$$

For better understanding, we also define constants $k_{1}$ and $k_{2}$.

$$
\begin{aligned}
& k_{1}=\frac{a_{2}-a_{1}}{2}, \\
& k_{2}=\frac{b_{2}-b_{1}}{2} .
\end{aligned}
$$

The situation is graphically represented in the figure 3 .

Figure 3: Range definition by using the distance from the centre of the area

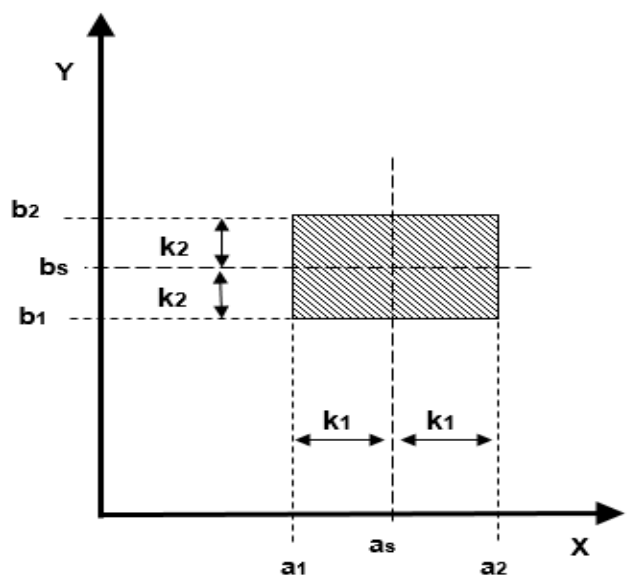

Source: own

Then the process of creating the restricted conditions begins. It is based on the following consideration: 
When the distance $X$ from the point as is greater than $k_{l}$ then the $Y$ coordinate is arbitrary. And when the distance $X$ from the point as is smaller than $k_{l}$ then the $Y$ coordinate must be greater than $b_{2}$ or smaller than $b_{1}$,

$$
\text { IF }\left(X-a_{S}\right)^{2} \leq{k_{1}}^{2} \quad \text { THEN } \quad\left(Y-b_{S}\right)^{2} \geq k_{2}{ }^{2} .
$$

The second powers ensure that all the numbers will be positive. However, the restrictions in this implication form are still not acceptable.

Fortunately, we can convert implication into disjunction by using

$$
(A \Rightarrow B) \Leftrightarrow(\neg A \vee B)
$$

We apply this mathematical rule to formula 9 so the conditions will be

$$
\left(X-a_{S}\right)^{2}>{k_{1}}^{2} \quad \text { OR } \quad\left(Y-b_{S}\right)^{2} \geq{k_{2}}^{2} .
$$

Nevertheless, converting the implication to disjunction is still not sufficient. We use the process stated in Barahona (1998) to convert the formula 11 into two formulas 12 and 13,

$$
\begin{aligned}
& \left(X-a_{S}\right)^{2} \geq{k_{1}}^{2}-M \cdot t \\
& \left(Y-b_{S}\right)^{2} \geq{k_{2}}^{2}-M \cdot(1-t)
\end{aligned}
$$

where $M$ is constant and $t$ is a binary variable.

As $M$ is chosen a relatively high number (standardly $M=1000$ ). The central point has the $X$ and $Y$ coordinates and these are interconnected by the variable $t$. This ensures the central point from lying in the prohibited area. We can have two types of situations based on the value of the variable $t$. In the situation where $t=0$, the $X$ coordinate of the central point must be outside the prohibited area.

This can be written as

$$
\left(X-a_{S}\right)^{2} \geq{k_{1}}^{2}-M \cdot 0 \text { resp. }\left(X-a_{S}\right)^{2} \geq{k_{1}}^{2} \text {. }
$$

The formula 14 says that the distance between " $X$ " and " $\mathrm{a}_{\mathrm{s}}$ " must be larger as " $k_{l}$ ". Then " $Y$ " coordinate of the central point may be any number,

$$
\left(Y-b_{S}\right)^{2} \geq{k_{2}}^{2}-M \cdot(1-0) \text { resp. }\left(Y-b_{S}\right)^{2} \geq{k_{2}}^{2}-M .
$$

where this condition always applies because $M$ is a high value.

Analogically the same apply for $t=1$ (The coordinate y must lie outside the prohibited area and $X$ can then lie everywhere.) More details about this problem can be found in Barahona (1998).

These conditions ensure that the restrictions are fulfilled. If the coordinate $X$ lies in the prohibited area, the value of $Y$ is either increased or decreased so that the point of the area will cross the prohibited area. In the mathematical solution (see figure 4), it is searched for values 
of the variables $X, Y$, and $t$ to the objective function $F$ given by the formula (see formula 1 ) to acquire the minimum.

Each time the solution will enter the prohibited area (obstacles for the central point) incurs one binary variable $t$.

\section{The result of the localization model of the central point}

The practical working of the model is explained in a particular situation. Let us illustrate it with a simple example: we have six stores positioned in different locations. Each store has its own position $x_{i}$ and $y_{i}$ and its volume of traffic $Q_{i}$, see table 1 . These values are the input values for computing the coordinates of the central point $x, y$.

Table 1: The positions and volume traffic for six stores

\begin{tabular}{|l|l|l|l|}
\hline \multicolumn{4}{|l|}{ INPUTS - POINTS } \\
\hline$i$ & $x_{i}$ & $y_{i}$ & $Q_{i}$ \\
\hline 1 & 0 & 0 & 10 \\
\hline 2 & 0 & 50 & 20 \\
\hline 3 & 50 & 0 & 10 \\
\hline 4 & 50 & 50 & 30 \\
\hline 5 & 10 & 10 & 18 \\
\hline 6 & 20 & 5 & 9 \\
\hline
\end{tabular}

Source: own

The output of the model is the figure 5 which shows computed coordinates of the central point (the green square) and fulfils the request of minimization of the objective function (the minimization of the whole traffic costs). The central point coordinates are $[20.3 ; 22.6]$ and the total traffic costs are equal to 3022.6.

Figure 4: Localization model of the central point

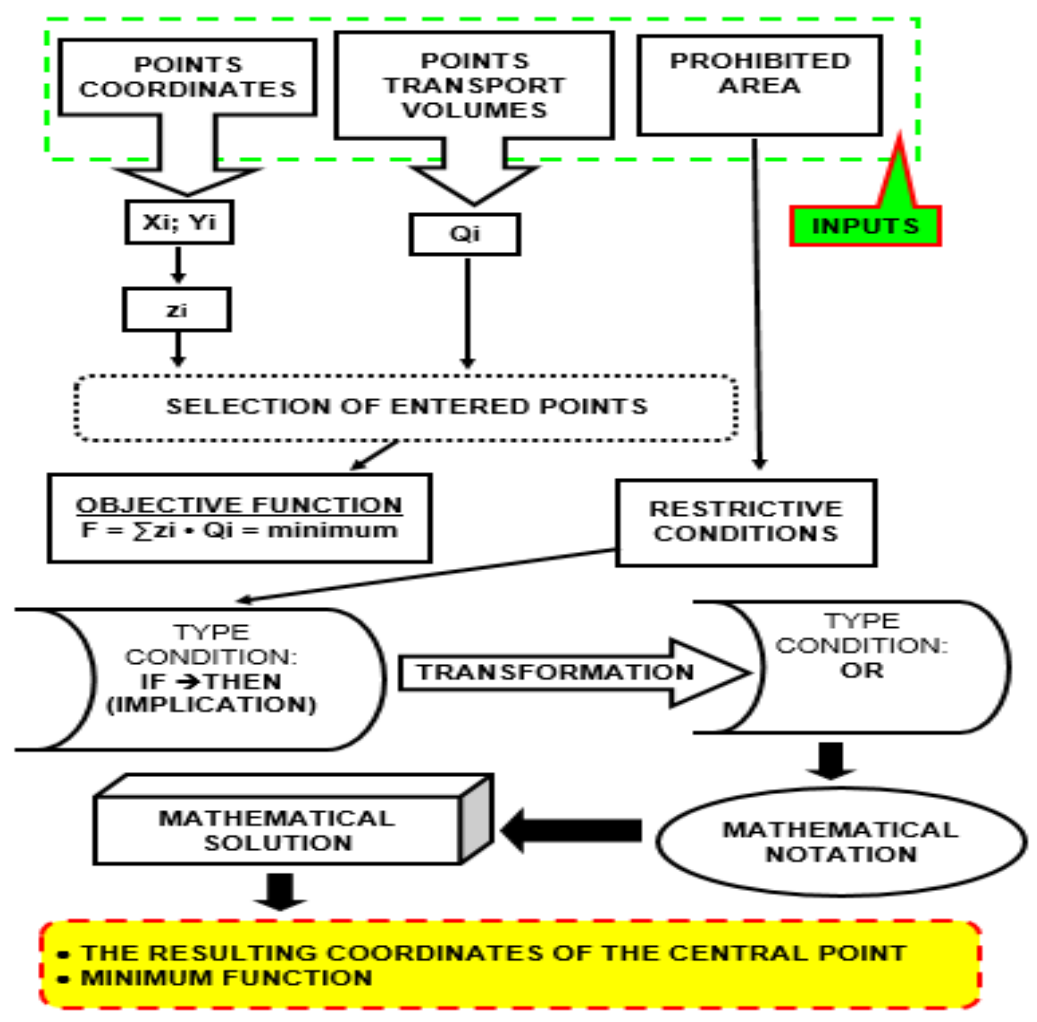

Source: own 
Figure 5: The solution of the model without respect to prohibited areas

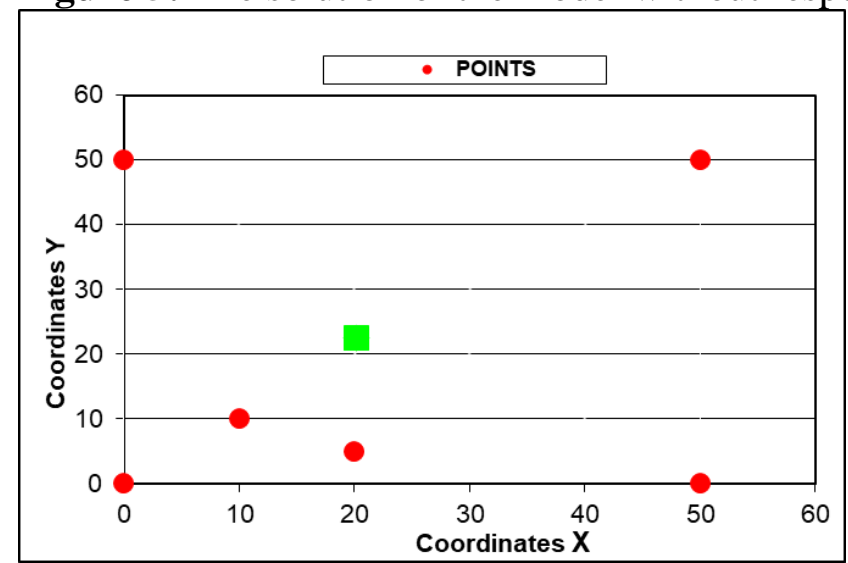

Source: own

The main benefit of the compiled model is the possibility to add one or more prohibited areas in the form of restrictive conditions. Table 2 shows one restrictive condition and it can be seen that this restriction prohibits the original solution (see figure 5) because now there is a prohibited area here.

Table 2: The prohibited areas

\begin{tabular}{|l|l|l|l|l|}
\hline \multicolumn{2}{|c|}{ PROHIBITED AREAS } \\
\hline \multirow{2}{*}{$N$} & \multicolumn{2}{|c|}{$x$} & \multicolumn{2}{c|}{$y$} \\
\cline { 2 - 5 } & FROM & TO & FROM & TO \\
\hline 1 & 10 & 35 & 15 & 40 \\
\hline 2 & & & & \\
\hline
\end{tabular}

Source: own

Principle of calculation describes the formulas 16, 17 and 18. The formula 16 represent the formula 3 with values from the table 1 .

$$
\begin{gathered}
F=10 \cdot \sqrt{(X-0)^{2}+(Y-0)^{2}}+20 \cdot \sqrt{(X-0)^{2}+(Y-50)^{2}} \\
+10 \sqrt{(X-50)^{2}+(Y-0)^{2}}+\cdots=\text { min } .
\end{gathered}
$$

The formula 17 represent the formula 12 with values from the table 2.

$$
\left(X-\frac{10+35}{2}\right)^{2} \geq\left(\frac{35-10}{2}\right)^{2}-1000 \cdot t
$$

The formula 18 represent the formula 13 with values from the table 2.

$$
\left(Y-\frac{15+40}{2}\right)^{2} \geq\left(\frac{40-15}{2}\right)^{2}-1000 \cdot(1-t)
$$

Where $t$ is ( 0 or 1$)$ binary variable. The result of the calculation is: $X=17.6$ and $Y=15.0$.

The model finds out the central point coordinates based on the minimal value of the objective function with respect to prohibited areas. The solution is depicted in the figure 6 . After the recalculation, the central point coordinates are $[17.6 ; 15.0]$. 
Figure 6: The solution of the model with respect to prohibited areas

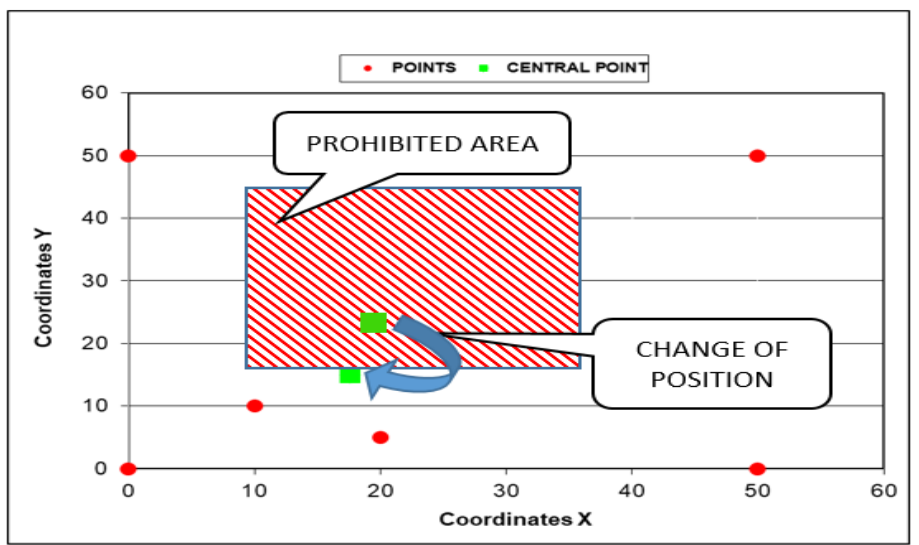

Source: own

The result gives an idea of the location of the central point (for example central warehouse). This is a mathematical model to describe the real situation. Unfortunately, this description will never be perfect.

\section{Conclusion}

At the present, it is recognized that location and time are the prominent underlying features for any scientific observation. Every experience and every observation that is formed by an intelligent mind in a scientific/engineering sense is fundamentally associated with location and time. Localization technology in today's "the smart" world has started to become popular. In the recent years, scientific researches solve problems using time, localization etc. As the smart applications in the world expand, need for localization in challenging environments grows. Today, a number of challenges are facing the localization science and technology as a fundamental enabling technology for the evolution of the so-called smart world.

This paper deals with determining the localization of a warehouse in interaction with its localization restriction. The aim is to design a model that would be a tool for determining the location of a warehouse. The correct location of the warehouse will contribute to transportation costs. In view of the robustness of the problem, it is necessary to use the exaggerated methods to find the optimal solution, i.e. a warehouse localize so that will minimize of transportation costs. The created model can also be a tool that will save time. Saving time lies in the speed of finding a solution for the localization of a warehouse.

The optimized deployment problem has been enhanced by the created model. There is a further extension of the real constraints, i.e. the optimum point usually cannot be a completely arbitrary coordinate system in practice. The basis for the creation of the model was to use special modifications linear programming and environment MS Excel. The model includes special restrictive conditions. It uses the implications raised when "A" must pay the condition "B".

Our model uses the Euclidean distance. This distance is shorter than real distance between points. This is a disadvantage of the model, but the authors assume that the difference (above mentioned) is the same for all distances. This will cause the value of the extreme will change, but not the position of the extreme (the position of the central point). Of course, there is a space for improvement of our model and for scientific work, for example by defining the correction coefficients to distance-extending.

Future use of the model will involve the extension of restrictive conditions. It is necessary to 
detail the "potential" to describe the position of a warehouse according to restrictive constraints. The follow-up research will focus on positioning, which will be entered using "polar coordinates".

\section{References}

[1] AIKENS, C.H., 1985. Facility location models for distribution planning. European Journal of Operational Research, 22(1), 263-279, ISSN 0377-2217. DOI: 10.1016/03772217(85)90246-2.

[2] BARAHONA, F. and D. JENSEN, 1998. Plant location with minimum inventory. Mathematical Programming, 83(1), 101-111, ISSN 0025-5610.

[3] GROS, I., 1996. Logistika. Praha: VŠCHT. ISBN 80-7080-262-6.

[4] HOLMBERG, K., 1999. Exact solution methods for uncapacitated location problem with convex transportation costs. European Journal of Operational Research, 114(1), 127-140, ISSN 0377-2217. DOI: 10.1016/S0377-2217(98)00039-3

[5] JABLONSKÝ, J., 2007. Programy pro matematické modelování. Praha: VŠE. ISBN 97880-245-1810-7.

[6] JOSSEF, P. and S. D. MARK, 1985. A warehouse location-routing problem. Transportation Research Part B: Methodological, 19B, 381-396, ISSN 0191-2615. DOI: 10.1016/0191-2615(85)90052-9.

[7] JUROVÁ, M. a kol., 2016. Výrobní a logistické procesy v podnikání. Praha: Grada. ISBN 978-80-247-5717-9.

[8] KAVAN, M., 2007. Projektový management inovací. Praha: ČVUT. ISBN 978-80-0103601-3.

[9] KLOSE, A. and A. DREXL, 2005. Facility location models for distribution system design. European Journal of Operational Research, 162(1), 4-29, ISSN 0377-2217. DOI: 10.1016/j.ejor.2003.10.031.

[10] OWEN, S. H. and M. S. DASKIN, 1998. Strategic facility location: a review. European Journal of Operational Research, 111(1), 423-447, ISSN 0377-2217. DOI: 10.1016/S0377-2217(98)00186-6.

[11] ROLLO, J., 1973. Praktické př́klady z operační analýzy. Praha: Redakce ekonomické a polytechnické literatury.

[12] SIDDHARTHA, S., 2002. A model and methodologies for the location problem with logistical components. Computers \& Operations Research, 29(9), 1173-1193, ISSN 03050548. DOI: 10.1016/S0305-0548(01)00023-5.

[13] SUN, H. et al., 2008. A bi-level programming model and solution algorithm for the location of logistics distribution centers. Applied Mathematical Modelling, 32(4), 610-616, ISSN 0307-904X. DOI: 10.1016/j.apm.2007.02.007.

[14] SYAM, S. S., 2002. A model and methodologies for the location problem with logistical components. Computers \& Operations Research, 29(9), 1173-1193, ISSN 0305-0548. DOI: $10.1016 / \mathrm{S} 0305-0548(01) 00023-5$.

[15] ZHOU, G., H. MIN and M. GEN, 2002. The balanced allocation of customers to multiple distribution centers in the supply chain network: a genetic algorithm approach. Computers \& Industrial Engineering, 43(1), 251-261, ISSN 0360-8352. DOI: 10.1016/S03608352(02)00067-0.g. 